\title{
BMJ open Effects of train noise and vibration on human heart rate during sleep: an experimental study
}

\author{
Ilona Croy, Michael G Smith, Kerstin Persson Waye
}

To cite: Croy I, Smith MG, Persson Waye K. Effects of train noise and vibration on human heart rate during sleep: an experimental study. BMJ Open 2013;3:e002655. doi:10.1136/bmjopen-2013002655

- Prepublication history for this paper are available online. To view these files please visit the journal online (http://dx.doi.org/10.1136/ bmjopen-2013-002655).

Received 30 January 2013 Revised 25 March 2013 Accepted 5 April 2013

This final article is available for use under the terms of the Creative Commons Attribution Non-Commercial 2.0 Licence; see http://bmjopen.bmj.com

Department of Occupational and Environmental Medicine, University of Gothenburg, Göteborg, Sweden

Correspondence to Dr Ilona Croy; Ilona.croy@amm.gu.se

\section{ABSTRACT}

Objectives: Transportation of goods on railways is increasing and the majority of the increased numbers of freight trains run during the night. Transportation noise has adverse effects on sleep structure, affects the heart rate (HR) during sleep and may be linked to cardiovascular disease. Freight trains also generate vibration and little is known regarding the impact of vibration on human sleep. A laboratory study was conducted to examine how a realistic nocturnal railway traffic scenario influences HR during sleep.

Design: Case-control.

Setting: Healthy participants.

Participants: 24 healthy volunteers (11 men, 13 women, 19-28 years) spent six consecutive nights in the sleep laboratory.

Interventions: All participants slept during one habituation night, one control and four experimental nights in which train noise and vibration were reproduced. In the experimental nights, 20 or 36 trains with low-vibration or high-vibration characteristics were presented.

\section{Primary and secondary outcome measures:}

Polysomnographical data and ECG were recorded.

Results: The train exposure led to a significant change of HR within 1 min of exposure onset $(p=0.002)$, characterised by an initial and a delayed increase of HR. The high-vibration condition provoked an average increase of at least $3 \mathrm{bpm}$ per train in $79 \%$ of the participants. Cardiac responses were in general higher in the high-vibration condition than in the lowvibration condition ( $p=0.006)$. No significant effect of noise sensitivity and gender was revealed, although there was a tendency for men to exhibit stronger HR acceleration than women.

Conclusions: Freight trains provoke HR accelerations during sleep, and the vibration characteristics of the trains are of special importance. In the long term, this may affect cardiovascular functioning of persons living close to railways.

\section{INTRODUCTION}

As the European market share of freight traffic is expected to increase from $8 \%$ in 2001 to $15 \%$ in $2020,{ }^{1}$ it is important to estimate the

\section{ARTICLE SUMMARY}

Article focus

- Noise of passing trains affects sleep and induces heart rate (HR) accelerations in humans.

- This may be linked to cardiovascular disease.

- Trains emit not only noise but also vibration, and the influence of vibration is poorly understood.

Key message

- Our study shows that freight train noise and vibration provoke HR accelerations in sleep. The $\mathrm{HR}$ response is characterised by two peaks, where the second one may depend on the vibration amplitude.

Strengths and limitations of this study

- The influence of nocturnal vibration on HR response has been studied for the first time under very well controlled laboratory conditions.

- However, further studies with an increased sample size should be carried out to analyse the influence of gender, age and sensitivity in more detail.

impact this may have on the health of persons living close by to railway lines. Railway noise is related to disturbed sleep, ${ }^{2-6}$ which in turn increases the risk of cardiovascular disease, ${ }^{7}$ supported by indications of increased cardiovascular disease in persons living close to railways. ${ }^{8}$ Understanding how railway noise and vibration influence the cardiovascular system in sleep is therefore necessary.

The sympathetic tone is reduced in sleep, which is reflected by a reduction of heart rate (HR). ${ }^{9}$ External noise events have the potential to disturb sleep and lead to event-related increase of HR. This has been shown for pure tones ${ }^{10}$ and more recently for traffic noise. ${ }^{11} 12$ Noise-induced HR changes do not seem to habituate during sleep $;{ }^{13}$ therefore, they might 'bear a pathogenic potential for the genesis of cardiovascular disease'. ${ }^{11}$ Evidence that long-term traffic exposure can increase the risk for cardiovascular disease comes from field studies. 
Babisch summarises that traffic exposure enhances the risk for hypertension by a factor of between 1.5 and $3 .^{14}$ An increased risk for myocardial infarction in persons living close to roads and railways has been found in several studies, ${ }^{15-18}$ although the effect sizes are rather small and the effects seem to be more pronounced in men. ${ }^{151618}$

Traffic noise influences sleeping structure ${ }^{19}$ and leads to increased awakenings ${ }^{19} 20$ throughout the night. People living close to busy roads and railways or in close proximity to airports therefore often report poor sleep quality. ${ }^{346}$ A Dutch study revealed that the number of persons reporting strong difficulties falling asleep due to traffic noise increased from $18 \%$ to $23 \%$ between 1998 and 2003. ${ }^{21}$ Disturbed sleep might be one factor leading to enhanced cardiovascular risk in persons exposed to traffic. It has been suggested that sleep disturbances contribute to cardiovascular disease through the pathway of enhanced inflammatory processes ${ }^{22}$ or, related to this, through the pathway of enhanced stress reaction affecting the cardiovascular system. ${ }^{23}$ In a field study, Carter et $a l^{24}$ examined the influence of nocturnal traffic exposure on seven older men with cardiac arrhythmia, who lived close to a busy road. They found an increased likelihood of single ventricular premature contractions (a form of cardiac arrhythmia) after noise peaks.

Two environmental exposures commonly arising from traffic are noise and vibration. As described, traffic noise disturbs sleep and leads to event-related HR changes, but the effect of traffic vibration is not well understood. Studies investigating annoyance show that (1) traffic vibration causes annoyance, (2) annoyance increases with increasing vibration level and (3) vibration enhances the annoying effect of noise. ${ }^{25-27}$ Furthermore, higher vibration amplitude is related to higher reported sleep disturbances in persons exposed to railway traffic. ${ }^{6}$ A study on human fetuses suggests that short experimental external vibration exposure alters sleep stage. ${ }^{28}$ Indications that vibration exposure is disadvantageous for cardiovascular function have been found in people exposed to high levels of vibration at work. $^{29} 30$

The effect of combined traffic vibration and noise on the cardiovascular system in sleep has not been examined, to the best of our knowledge. It is the aim of the present study to detect if nocturnal noise and vibration exposure from freight trains provoke HR accelerations.

\section{METHODS}

\section{Participants and procedure}

Twenty-four volunteers (11 men, 13 women, 19-28 years, mean age $22.9 \pm 2.8$ years) slept in our sleep laboratory. Twenty-three were students and one was in full-time employment, recruited by public advertisements placed around the campus of the University of Gothenburg. Eligible persons were required to be aged between 18 and 30 years, in healthy condition, maintain normal sleeping patterns and not use tobacco products. To decrease the probability of subclinical breathing difficulties or apnoea, participants were required to have a body mass index within the normal range 18.5-24.99. ${ }^{31}$ Following initial screening, hearing was tested before volunteers were accepted. Manual audiometric testing was conducted using an Entomed SA201 ${ }^{\mathrm{II}}$ according to ISO 8253-1. Left and right ears were tested separately at frequencies of 250, 500, 1000, 2000, 3000, 4000, 6000 and $8000 \mathrm{~Hz}$ with hearing considered to be normal if measured thresholds were not more than a screening level of $20 \mathrm{~dB} \mathrm{HL}$.

The participants were instructed to begin attempting to fall asleep at 23:00 each night, were awoken by an alarm call at 07:00 each morning, and were prohibited from sleeping outside of this period. Before attending, they were asked about their noise sensitivity on a 5-point Likert scale. Fourteen participants $(8$ men and 6 women) rated themselves as being noise insensitive (points 1-2) and 10 rated themselves as being noise sensitive (points 3-5). For each participant, the study consisted of one habituation night and one control night preceding four experimental nights in which simulated trains passed. The arrangement of the experimental nights was randomised across participants. Gender and noise sensitivity was approximately equally spread around the randomisation table. In two of the four experimental nights, the participants were exposed to 20 trains per night with all trains having high vibration on one night and low vibration on the other night (High20 and Low20, respectively). On the remaining two nights, they were exposed to 36 trains per night, again with either high or low vibrations (High36 and Low36). The acoustic signal for the trains was not varied with vibration amplitude. There were more train passages between the periods of 23:00-01:00 and 05:00-07:00 to reflect typical real-world scenarios.

The sleep laboratory consists of three individual rooms isolated from external noise and vibration, furnished to simulate a typical bedroom with a bed, chairs, a desk and a small chest of drawers. Eighty-eight ceiling loudspeakers reproduced the low-frequency content of noise below $125 \mathrm{~Hz}$, and higher frequencies were generated by two loudspeaker cabinets in the room corners. Because of the unrealistically low background noise levels in the rooms $(<14 \mathrm{dBA})$, for the duration of the trial, artificial ventilation noise was introduced at a level of $25 \mathrm{dBA}$ measured at the pillow position on the bed. In addition to the bedrooms, the participants had private access to a shared communal space outfitted with a kitchen, dining area and living area with a sofa and television. They were free to come and go as they desired during the daytime, being required to arrive by 20:00 each evening to ensure rest prior to bedtime and to allow sufficient time for electrode attachment.

Vibration and noise exposure were similar to that in another study conducted in our laboratory ${ }^{32}$ and are only summarised here. Five different train passages were 
synthesised based upon analysis of the accelerometer and sound level measurements performed in the field. Noise signals were low pass filtered to correspond to a fully closed window. The vibration exposure was an amplitude-modulated $10 \mathrm{~Hz}$ signal applied along the lengthwise horizontal axis of the bed by electrodynamic shakers with a frequency response of $5-40 \mathrm{~Hz}$ mounted to the underside of the bed frame. The vibration began when the train noise signal exceeded an A-weighted equivalent level $\left(\mathrm{L}_{\mathrm{Aeq}}\right)$ of $35 \mathrm{~dB}$, ensuring masking of any audible mechanical operation noise. Further acoustic and vibration data for each individual train are presented in table 1 .

\section{Cardiac response and polysomnography}

During all experimental nights, physiological data were recorded using ambulatory polysomnogram devices (SOMNOscreen plus PSG+, SOMNOmedics GmbH, Germany). The time resolution of the onset was 4.7 $\pm 3.4 \mathrm{~s}$.

Cardiac activity was recorded via a modified lead II torso placement ECG at a sampling frequency of $256 \mathrm{~Hz}$ as per the American Academy of Sleep Medicine. ${ }^{33}$ To identify sleep stage, EEG, electrooculogram and submental electromyogram were also recorded using standardised surface electrode placements and sampling and filter frequencies. To ensure good signal quality, following electrode attachment it was checked that the electrical impedance of each contact was $\leq 5 \mathrm{k} \Omega$. Thirty second epoch sleep staging was performed manually by a trained sleep technician. Additionally, participants wore two effort belts to record breathing rates and a finger pulse oximeter to record blood oxygen saturation, plethysmogram and pulse information, although these data will not be reported here. Owing to a technical fault, ECG was not obtained for one participant (female, noise sensitive) in the High20 night and therefore could not be included in analysis.

\section{Event-related analysis and control condition}

In order to examine event-related changes of HR, data from the four exposure nights were analysed. The continuously recorded ECG (sampling frequency of $256 \mathrm{~Hz}$ ) was converted into HR (in bpm) in $1 \mathrm{~s}$ intervals through the whole night. EEG and ECG recordings were synchronised with the train exposure events, thus allowing a direct temporal association between the occurrence of a train and the participant's HR reaction and sleep stages. Analysis revealed that $9.9 \%$ of the train onsets occurred during wake stage, $8.1 \%$ during stage $\mathrm{N} 1,42 \%$ during stage N2, 21.4\% during stage N3 and $17.8 \%$ during rapid eye movement (REM).

The procedure of HR analysis is visualised in figure 1 . HRs below 35 and above $130 \mathrm{bpm}$ were excluded from the analysis. ${ }^{11} 34$ This was the case for $4.1 \%$ of the events. For analysis of event-related HR change (bpm), only train events where participants were asleep were considered. This approach was chosen because Griefahn et $a l^{11}$ showed that HR response to traffic noise differs depending on whether the participants do or do not awake. The relatively few trains per night in our study do not allow additional examination of HR response in the case of awakenings. An event-related awakening has been defined as a sleep stage change to Wake from any other stage in at least one of the two epochs (30 s) following the train onset. ${ }^{35}$ The first of these was determined by that having at least $15 \mathrm{~s}$ under influence of the event. Additionally, events for which the participants were awake in the epoch preceding train onset were excluded from the analysis. The whole procedure left $72.4 \%$ of the train events in the low-vibration condition and $66.1 \%$ of the train events in the high-vibration condition for analysis. In accordance with the literature, the screening interval for cardiac activations was set to $60 \mathrm{~s}$ after train onset. ${ }^{11}{ }^{34}$ In order to analyse change of HR, the average cardiac response from the $10 \mathrm{~s}$ preceding the train event was used as a baseline value for each given event and subsequently subtracted from the cardiac response in each of the $601 \mathrm{~s}$ time intervals following the train onset.

In order to examine if there was a train-related change of HR at all, fake trains' were calculated. Fake trains were defined as time intervals of $60 \mathrm{~s}$ not accompanied by a real train event, distributed at time intervals approximately equally spaced between the actual exposure events. Twenty of these were introduced in the Low20

Table 1 Vibration and noise parameters applied to individual trains

\begin{tabular}{|c|c|c|c|c|c|c|c|c|}
\hline \multirow[b]{2}{*}{ Train } & \multicolumn{2}{|c|}{$\begin{array}{l}\text { Number of passages } \\
\text { per night }\end{array}$} & \multicolumn{4}{|c|}{ Noise exposure } & \multicolumn{2}{|c|}{ Vibration exposure (same for all trains) } \\
\hline & $\begin{array}{l}20 \text { Trains/ } \\
\text { night }\end{array}$ & $\begin{array}{l}36 \text { Trains/ } \\
\text { night }\end{array}$ & $\begin{array}{l}\mathrm{L}_{\mathrm{AEq}} \\
(\mathrm{dB})\end{array}$ & $\begin{array}{l}\text { LAFmax } \\
\text { (dB) }\end{array}$ & $\begin{array}{l}t>35 d B \\
(s)\end{array}$ & $\begin{array}{l}T_{10 \%-} \\
90 \%(s)\end{array}$ & $\begin{array}{l}\text { Unweighted } \\
\text { acceleration } \\
\left(\mathrm{m} / \mathrm{s}^{2} \mathrm{rms}\right)\end{array}$ & $\begin{array}{l}W_{d} \text { Weighted peak } \\
\text { acceleration }\left(\mathrm{m} / \mathrm{s}^{2}\right)\end{array}$ \\
\hline 1 & 4 & 8 & 44.0 & 48.4 & 11.5 & 8.9 & & \\
\hline 2 & 5 & 8 & 42.7 & 47.2 & 46.2 & 9.8 & High $=0.072$ & High $=0.0204$ \\
\hline 3 & 4 & 8 & 44.5 & 49.8 & 23.7 & 8.4 & Low $=0.036$ & Low $=0.0102$ \\
\hline 4 & 5 & 8 & 45.6 & 49.8 & 29.2 & 7.9 & & \\
\hline 5 & 2 & 4 & 42.4 & 47.2 & 56.9 & 9.2 & & \\
\hline
\end{tabular}




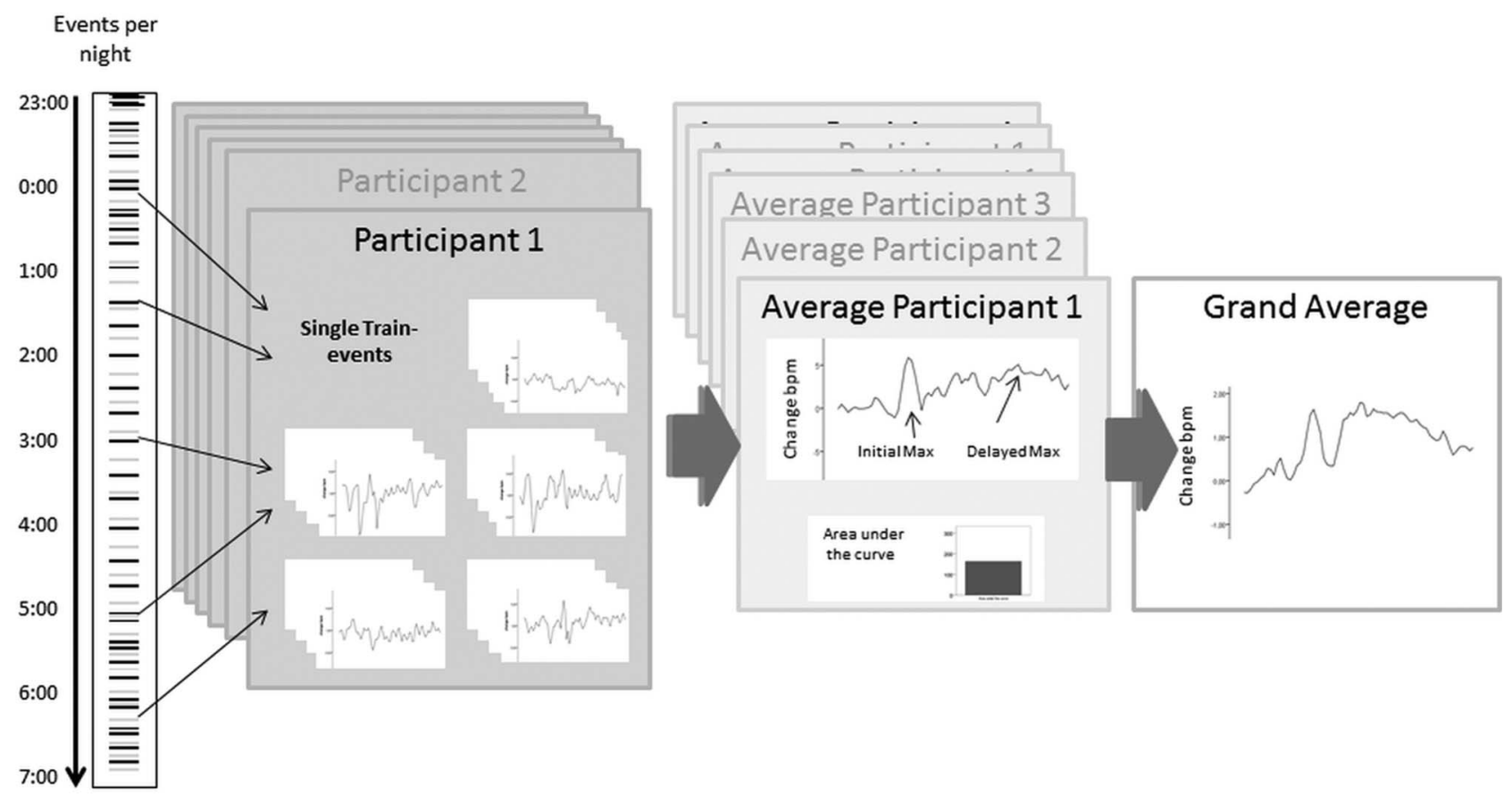

Figure 1 Visualisation of the analytical procedure. For each of the four experimental nights, HR data are taken out for each of the train-events (black lines of the events per night) for each participant. Data are checked for artefacts and wake stage and then sampled into one average HR response for each participant with the corresponding initial maximum, delayed maximum and area under the curve parameters. The grand average is built over all of the participants. The very same procedure is applied to the fake events (grey lines of the events per night).

and High20 nights and 36 in the Low36 and High36 nights. Analysed HR data for these consisted of $70 \mathrm{~s}$, where $10 \mathrm{~s}$ served as baseline for the following $60 \mathrm{~s}$. As with the real exposures, data where polysomnographical analysis indicated that participants were awake before onset or awoke during the two epochs following onset were excluded. All event-related $60 \mathrm{~s}$ periods were subsequently averaged over nights with low or high vibration, respectively. The whole procedure was the same for each of the four nights to avoid any potential investigator bias.

Griefahn et $a l^{11}$ report a maximum increase of HR about $13.2 \mathrm{~s}$ after event onset. We took this time interval $\pm 3 \mathrm{~s}$ as a base for the searching area for the maximum increase between 10 and $16 \mathrm{~s}$ after train onset.

\section{Statistical analysis}

Data were analysed using SPSS V.20 (SPSS Inc, Illinois, USA). In order to identify any overall effect of trains on $\mathrm{HR}$, the integral of the HR response was taken to determine the area under the curve $(\mathrm{AuC})$ for the $60 \mathrm{~s}$ after train onset. An analysis of variance (ANOVA) for repeated measurements was calculated comparing AuC in three factors: event (fake vs real-train), vibration level (low vs high) and number of trains (20 vs 36 ). The effects of noise sensitivity and gender were also analysed using ANOVA for repeated measurements with the between-subject factor noise sensitivity/gender and the within-subject factor vibration level (low vs high). Post hoc comparisons are reported Bonferroni-corrected. The level of significance is set at $\alpha=0.05$.

\section{RESULTS}

Influence of train noise and vibration on HR

The AuC analysis for the change of HR $60 \mathrm{~s}$ after event onset revealed a significant main effect of the train, indicating that train events lead to an enhanced change of $H R$ compared with the fake events (F22,1=12.0, $\mathrm{p}=0.002)$. Furthermore, there were significantly more awakenings in the train vs fake events (F22,1=40.3, $\mathrm{p}<0.001)$.

There was a significant main effect of vibration level. A higher change of HR and an increased number of awakenings could be observed in the high vibration level compared to the low-vibration level (HR: F22,1=7.6; $\mathrm{p}=0.01$; awakenings: $\mathrm{F} 22,1=6.5 ; \mathrm{p}=0.014$ ). The number of trains had no significant influence on the HR change. The results are displayed in table 2.

Averaged over all trains within one night, an increase of HR of at least $3 \mathrm{bpm}$ was observed in $54 \%$ of the participants in Low36, $52 \%$ in the Low20 condition, $74 \%$ in the High20 night and 79\% of participants in the High36 night. For the fake train events, an average increase of HR of at least $3 \mathrm{bpm}$ was observed in only $17-38 \%$ of the participants, depending on the exposure night.

As no significant influence of the number of trains was revealed, the four exposure conditions were combined into two conditions: a high-vibration condition and a low-vibration condition. This approach is advantageous for the signal-noise ratio, because in this way the number of analysable trains could be increased to 56 . For calculating the low-vibration condition, train events from the Low20 and Low36 nights that matched the 
Table 2 Analysis of event-related HR response for each of the four exposure nights and combined for low-vibration and high-vibration exposure

\begin{tabular}{|c|c|c|c|c|}
\hline & \multicolumn{2}{|l|}{ Low vibration } & \multicolumn{2}{|l|}{ High vibration } \\
\hline & $\begin{array}{l}20 \text { Trains/night } \\
\mathrm{N}=24 \\
\text { Mean (SD) }\end{array}$ & $\begin{array}{l}36 \text { Trains/night } \\
\mathrm{N}=23 \\
\text { Mean (SD) }\end{array}$ & $\begin{array}{l}20 \text { Trains/night } \\
\mathrm{N}=23 \\
\text { Mean (SD) }\end{array}$ & $\begin{array}{l}36 \text { Trains/night } \\
\mathrm{N}=24 \\
\text { Mean (SD) }\end{array}$ \\
\hline \multicolumn{5}{|l|}{ HR AuC } \\
\hline Train & $41.7(114.5)$ & $77.2(103.0)$ & $19.4(77.6)$ & $52.3(86.8)$ \\
\hline Fake & $-4.6(83.7)$ & $0.2(54.4)$ & $-7.4(51.5)$ & $2.2(60.9)$ \\
\hline \multicolumn{5}{|c|}{ Number of event-related awakenings per night } \\
\hline Train & $3.3(2.3)$ & $4.2(2.6)$ & $5.2(3.2)$ & $5.6(3.4)$ \\
\hline Fake & $1.5(0.7)$ & $1.5(0.6)$ & $1.2(0.4)$ & $1.8(0.8)$ \\
\hline $\begin{array}{l}\text { Event-related HR change of at least } \\
3 \mathrm{bpm}\end{array}$ & \multicolumn{4}{|c|}{ Number of participants (percentage of sample population) } \\
\hline Train & $15(62.5 \%)$ & $17(73.9 \%)$ & $13(54.2 \%)$ & $19(79.2 \%)$ \\
\hline \multirow[t]{2}{*}{ Fake } & $9(37.5 \%)$ & $8(34.8 \%)$ & $4(16.7 \%)$ & $4(16.7 \%)$ \\
\hline & \multicolumn{2}{|c|}{ Low vibration Mean (SD) } & \multicolumn{2}{|c|}{ High vibration Mean (SD) } \\
\hline \multicolumn{5}{|c|}{ 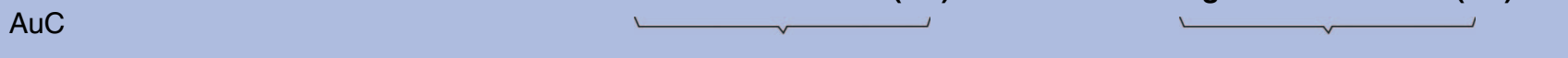 } \\
\hline Train & \multicolumn{2}{|c|}{$21.2(81.8)$} & \multicolumn{2}{|c|}{$62.3(81.4)$} \\
\hline \multicolumn{5}{|l|}{ Initial response } \\
\hline Train & \multicolumn{2}{|c|}{$1.6(1.8)$} & \multicolumn{2}{|c|}{$2.3(2.0)$} \\
\hline Fake & \multicolumn{2}{|c|}{$0.7(0.9)$} & \multicolumn{2}{|c|}{$0.7(1.0)$} \\
\hline \multicolumn{5}{|l|}{ Delayed response } \\
\hline Train & \multicolumn{2}{|c|}{$2.6(2.4)$} & \multicolumn{2}{|c|}{$3.7(2.8)$} \\
\hline Fake & \multicolumn{2}{|c|}{$1.1(1.0)$} & \multicolumn{2}{|c|}{$1.3(0.9)$} \\
\hline \multicolumn{5}{|l|}{ Sleep stage-related (train events only) } \\
\hline \multicolumn{5}{|l|}{$\mathrm{AuC}$} \\
\hline Stage N3 & \multicolumn{2}{|c|}{$25.1(166.9)$} & \multicolumn{2}{|c|}{$79.7(114.8)$} \\
\hline Stage N2 & \multicolumn{2}{|c|}{$30.2(95.8)$} & \multicolumn{2}{|c|}{$53.2(90.3)$} \\
\hline REM & \multicolumn{2}{|c|}{$42.6(162.4)$} & \multicolumn{2}{|c|}{$113.0(203.1)$} \\
\hline \multicolumn{5}{|l|}{ Initial response } \\
\hline Stage N3 & & 2.7) & & (4.0) \\
\hline Stage N2 & & 2.2) & & (1.9) \\
\hline REM & & 2.8) & & (3.3) \\
\hline Delayed response & & & & \\
\hline Stage N3 & & 4.9) & & (4.1) \\
\hline Stage N2 & & 3.6) & & (3.4) \\
\hline REM & & 4.1) & & $(5.8)$ \\
\hline $\begin{array}{l}\text { Area under the curve (AuC), number of e } \\
\text { participants with an event-related change } \\
\text { delayed maximal increase of } \mathrm{HR} \text { are pres } \\
\text { response is calculated as maximal increa } \\
\text { the differences between the initial and de }\end{array}$ & $\begin{array}{l}\text {-related awakening } \\
\text { IR of at least } 3 \mathrm{bpm} \\
\text { ed for the combined } \\
\text { vithin the first } 10-15 \\
\text { d increase of } \mathrm{HR} \text {. }\end{array}$ & $\begin{array}{l}\text { ial and delayed max } \\
\text { presented for each } \\
\text { vibration and high-vi } \\
\text { - }-48 \mathrm{~s} \text { after train on }\end{array}$ & $\begin{array}{l}\text { increase of heart ra } \\
\text { four experimental } r \\
\text { on conditions. Cave } \\
\text { This difference in se }\end{array}$ & $\begin{array}{l}\text { IR) and number of } \\
\text { s. AuC, initial and } \\
\text { initial and delayed } \\
\text { area explains partly }\end{array}$ \\
\hline
\end{tabular}

inclusion criteria described in the methods section were averaged to obtain one low-vibration response. The same method was performed for the high-vibration condition. This procedure was repeated for the fake events, so that the resulting responses for the low-vibration and highvibration exposures for both the actual and phantom events could be compared.

\section{Characteristics of the HR curve}

The HR curve shows a biphasic characteristic (see figure 2A). After approximately $9 \mathrm{~s}$, a short initial response characterised by increase of HR takes place, lasting for around $6 \mathrm{~s}$. This initial response is significantly above the baseline between 10 and $13 \mathrm{~s}$ for the low-vibration condition, and between 10 and $15 \mathrm{~s}$ for the high-vibration condition ( $\mathrm{t}$ test, $\mathrm{p}<0.05$ ). This response is in accordance with the proposed search area of the maximum increase.

An additional delayed response can also be observed. This response is characterised by a second increase of HR beginning around $17 \mathrm{~s}$ following train onset and with a duration of around $20 \mathrm{~s}$ for the low-vibration condition and about $30 \mathrm{~s}$ for the high-vibration condition. The delayed response is significantly above the baseline between 21 and $22 \mathrm{~s}$ for the low-vibration condition, and between 20 and $48 \mathrm{~s}$ for the high-vibration condition $(\mathrm{t}$ test, $\mathrm{p}<0.05)$. This same response could be seen for each of the five individual train types (see figure $2 \mathrm{~B}$ ) 


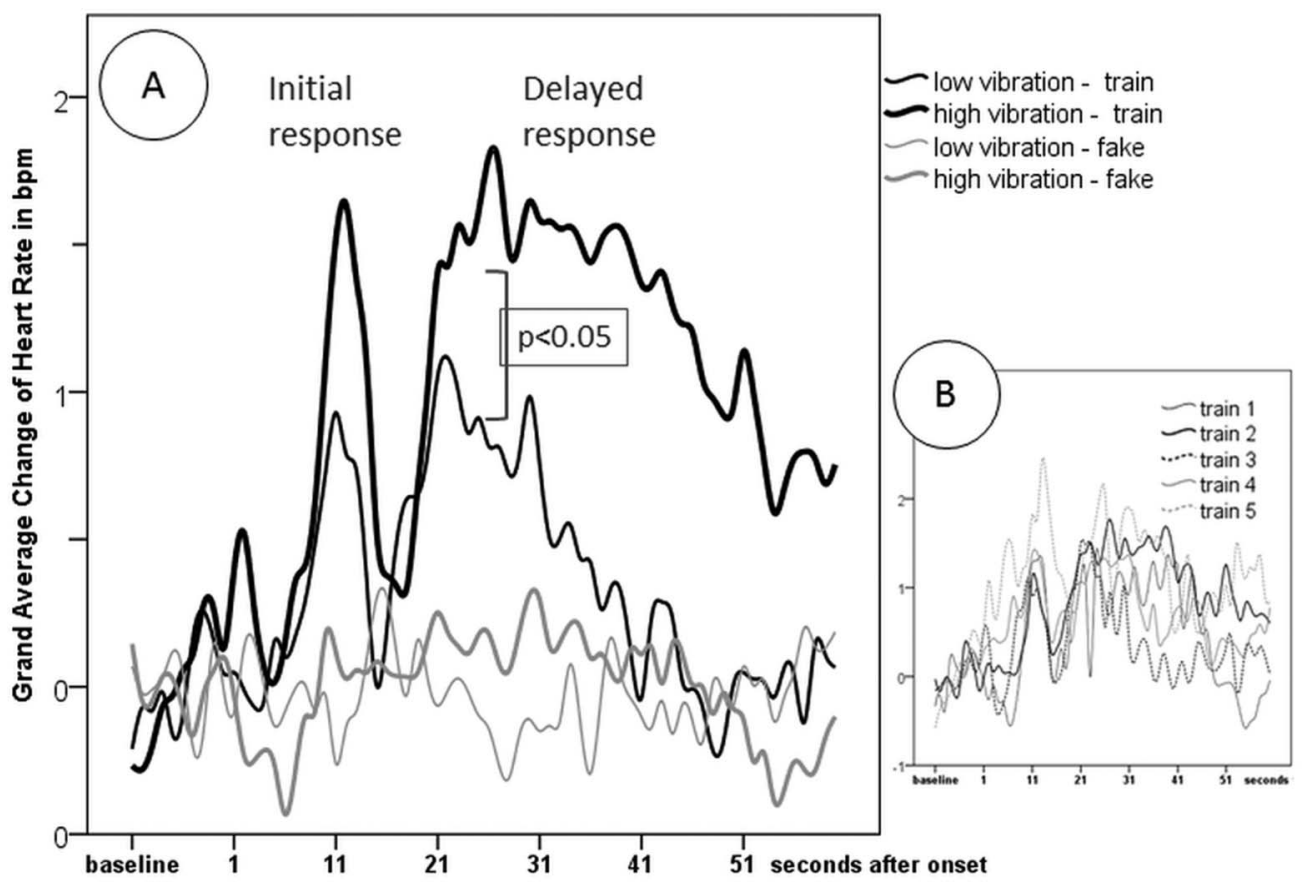

Figure 2 (A) Averaged HR response following the train events and fake events, respectively, in the low and high vibration exposures. In figure $1 \mathrm{~A}$, a clear HR increase after train events can be seen, while HR stays at baseline for fake events. The HR response can be divided into two components. An initial response occurring around 10-15 s after train onset and a delayed response occurring about 17-48 s after train onset. The delayed response is significantly enhanced in the high-vibration versus Low-vibration exposure. In figure 1B, the averaged HR reaction in the high-vibration condition is visualised for each of the five different train types. Although the different number of trains does not allow direct comparison, it can be seen that in principle the same characteristics of the HR reaction is apparent for each train.

This response pattern could be observed in the individual participants, but the time delay after event onset showed a great variability. The individual maximum for

Table 3 Train-related HR characteristics in relation to gender and noise sensitivity of the participants

\begin{tabular}{lcc}
\hline & $\begin{array}{c}\text { Low vibration } \\
\text { Mean (SD) }\end{array}$ & $\begin{array}{c}\text { High vibration } \\
\text { Mean (SD) }\end{array}$ \\
\hline Gender & & \\
Men N=11 & $48.1(73.0)$ & $81.2(96.8)$ \\
AuC & $1.7(1.4)$ & $2.0(1.9)$ \\
Initial response & $3.5(2.8)$ & $4.8(3.7)$ \\
Delayed response & & \\
Women N=13 & $-1.6(84.6)$ & $46.2(65.4)$ \\
AuC & $1.5(2.1)$ & $2.6(2.2)$ \\
Initial response & $1.8(1.7)$ & $2.8(1.5)$ \\
Delayed response & & \\
Noise sensitivity & & \\
Non-sensitive N=14 & $24.0(62.0)$ & $63.8(93.3)$ \\
AuC & $1.1(1.3)$ & $2.0(2.0)$ \\
Initial response & $2.3(2.0)$ & $4.0(3.4)$ \\
Delayed response & & \\
Sensitive N=10 & $17.2(107.3)$ & $60.1(65.9)$ \\
AuC & $2.4(2.2)$ & $2.8(2.1)$ \\
Initial response & $3.0(2.9)$ & $3.4(2.0)$ \\
Delayed response & & \\
\hline HR, heart rate; AuC, area under the curve. & \\
& &
\end{tabular}

each participant within the range of the initial response (10-15 s) and the delayed response (17-50 s) was calculated and is reported in table 2.

For the initial response and for the delayed response, ANOVA for repeated measurements revealed a significant main effect of the event, indicating that the train-events led to an enhanced change of HR compared with the fake-events (initial response: $\mathrm{F} 23,1=13, \mathrm{p}=0.001$; delayed response: $\mathrm{F} 23,1=15.5, \mathrm{p}=0.001$ ).

The vibration level had no significant influence on the initial increase of HR (F23,1=2.1, n.s.), but affected the delayed response. A higher delayed increase of HR was observed in the high vibration level compared to the low vibration level $(\mathrm{F} 23,1=9.4, \mathrm{p}=0.006)$.

\section{Effect of order}

The participant's HR responses of the four nights were compared with respect to the order of experimental nights using ANOVA for repeated measurements. There was no significant influence of order of experimental nights on the AuC response (F22,3=1.7, n.s.), as well as for the initial $(\mathrm{F} 22,3=2.0$, n.s. $)$ or delayed response (F22,3=0.8).

\section{Influence of sleep stage}

The AuC, the initial maxima and the delayed maxima were compared in the sleep stages N3, N2 and REM. For 
the wake stage and for stage $\mathrm{N} 1$, there were too few events to allow for comparison. The results are presented in table 2.

ANOVA for repeated measurements using the withinsubject factors sleep stage (stages N3, N2 and REM) and vibration level (low vs high) was calculated.

The overall AuC revealed no significant influence of sleep stage (F23,2=1.1, n.s.). The initial response revealed a significant influence of sleep stage (F23,2=5.1 $\mathrm{p}=0.009$ ). Bonferroni-corrected post hoc comparison reveals that the initial increase of HR was significantly higher in REM than in stage N2 sleep $(p=0.002)$. The same significant pattern was seen in the delayed response $(\mathrm{F} 23,2=4.8 \mathrm{p}=0.013)$. Here again, a post hoc comparison showed that HR increase was higher in REM sleep than in stage $\mathrm{N} 2(\mathrm{p}=0.017)$.

\section{Influence of noise sensitivity and gender Effect of sensitivity}

$\mathrm{AuC}$, initial maxima and delayed maxima of HR change are compared between participants with low $(\mathrm{N}=14)$ and high $(\mathrm{N}=10)$ noise sensitivity. The results are displayed in table 3. No significant main effects of noise sensitivity were found in $\mathrm{AuC}(\mathrm{F} 22,1=0.007$, n.s.) as well as in the initial $(\mathrm{F} 22,1=2.8, \quad$ n.s. $)$ or delayed response $(\mathrm{F} 22,1=0.004$, n.s.). There were no significant interactions between noise sensitivity and vibration level.

\section{Effect of gender}

The results of comparisons between men $(\mathrm{N}=11)$ and women $(\mathrm{N}=13)$ are shown in table 3. No significant differences were found in $\mathrm{AuC}(\mathrm{F} 22,1=2.5$, n.s.) or in the HR initial (F22,1=0.5, n.s.) between genders. There was a tendency for men to exhibit a stronger increase of HR in the delayed response $(\mathrm{F} 22,1=4.1, \mathrm{p}=0.055)$.

\section{DISCUSSION}

Our data show that train noise and vibration exposure lead to an increased number of awakenings and cardiac arousals, and that vibration might be of particular importance. HR acceleration with two maxima was observed following train noise and vibration. One rapid and distinct initial $\mathrm{HR}$ increase is evident around $9 \mathrm{~s}$ after train onset and a lengthier delayed increase is observed starting about $17 \mathrm{~s}$ after train onset. In a similar study dealing with traffic noise alone, Griefahn et $a l^{11}$ found an increase of HR matching our initial response but no delayed increase. A similar initial increase of HR has been found for pure tones during sleep. ${ }^{36}$ We propose that the second plateau is due to the additional vibration exposure, which seems to either act in isolation to result in cardiac response, or alternatively enhance or interact with any delayed effects of rail noise on HR. Supporting this interpretation, we see a significant difference between the low-vibration and high-vibration levels for the delayed, but not for the initial increase. The combined exposure might be a more pronounced alarming signal than noise alone and the HR alterations endure even after cessation of the actual exposure. In accordance with the previous literature on sleep disturbance due to noise exposure, ${ }^{10-12}$ the highest alterations of HR were found in REM sleep. This was observed for both the initial and delayed response.

Cardiac arousals are very likely induced by brain stem activation. ${ }^{37}$ This subcortical activation may present a form of primary arousal in sleep and-depending on the strength of activation and on sleep stage-lead to cortical activation and arousal. Increased HR indicates subcortical arousal and enhances the probability of a cortical arousal with implications for sleep structure. ${ }^{37}$ However, even HR acceleration without concomitant cortical arousal has been shown to have adverse effects on sleep structure. Guilleminault $e t a l^{8}$ showed that forced subcortical arousals accompany disturbed sleep and the persons are not necessarily aware of their disturbed sleep the following morning.

In the short term, arousals have positive effects by ensuring a higher level of behavioural responsiveness in the presence of external stimuli, while sleep is protected as far as possible. ${ }^{39}$ However, in the long term, increased autonomic reaction might be harmful. As Kohler and Stradling ${ }^{40}$ point out in a review paper, recurrent arousals are one of the mechanisms leading to cardiovascular disease in obstructive sleep apnoea. In this manner, the autonomic arousals provoked by passing trains may-if continuing over a number of years - contribute to the slightly enhanced myocardial infarction risk that has been found in people living in areas with high traffic exposure. ${ }^{15-18}$ The study of Tassi et a $a \bar{l}$ suggests that people living in areas with high railway noise for more than 10 years can partly adjust their sleep to this adverse exposure. However, even after such a long-term exposure, significant alterations of HR due to a nocturnal railway traffic scenario have been found. In epidemiological studies, the effects of noise exposure alone are rather small. ${ }^{15-18}$ Our data suggest that the effect of chronic traffic exposure on cardiovascular disease might be higher if vibration is additionally taken into account. As described in the methods of this paper, we excluded events from the analysis where the persons woke up. This approach allows a focused estimation of HR reaction from traffic noise during sleep. However, as HR reactions are usually greater if accompanied by awakenings, ${ }^{11}$ our results very likely underestimate the effects. We found an average train-related increase of $3 \mathrm{bpm}$ in $79 \%$ of participants, supporting previously reported data. ${ }^{10}$ It is not possible with the present study design to estimate the clinical relevance of these results. However, an increase of HR in sleep perhaps reflects a higher sympathetic tone ${ }^{9}$ and this may contribute to the enhanced risk for hypertension in long-term traffic exposure. $^{14}$

Our results are less clear regarding the impact of interindividual differences. Previous epidemiological 
research has shown that persons who state being sensitive to noise report greater sleeping problems due to traffic than non-sensitive persons. ${ }^{41}$ However, we found no significant effect of self-reported noise sensitivity on HR response towards nocturnal train events. During the day, it has been shown that self-declared highly noise sensitive persons have higher cardiovascular responses towards different ecologically relevant sounds, including traffic noise. ${ }^{13}$ The sample size of sensitive and nonsensitive participants in our study is relatively small, and therefore non-significant results in particular have to be interpreted with caution. The sample size also limits any interpretation of gender effects. In coherence with the study of Griefahn, we found no significant gender differences in the initial HR amplitude. ${ }^{11}$ We found a tendency for enhanced delayed HR response in men with a rather strong effect size. This corresponds to results from several field studies, where enhanced traffic exposure related cardiovascular diseases were found in men. $^{151618}$

We are aware of the limitations of the study: Regarding internal validity, the time resolution of the measurement could potentially lead to a smoothing of the averaged data, underestimating our results. Nevertheless, a clear effect of enhanced HR reaction in high vibration conditions can be seen. We argue that vibration exposure is responsible for the second plateau. However, a vibration-alone condition, that is, in the absence of noise, is needed to confirm this. With respect to external validity, the study is limited to the homogeneous group of young and healthy participants. To generalise the results, a broader age range would be preferable and the study should be replicated in field conditions.

In conclusion, the combined exposure of freight train noise and vibration influenced HR during sleep, whereby HR amplitudes increase with increasing vibration level. This provoked acceleration may affect cardiovascular functioning in the long term ${ }^{511}$ and could be a mechanism explaining the previous findings of cardiovascular disease in persons exposed to traffic in general $^{14-18}$ and rail traffic in particular. ${ }^{8}$ To study the specific influence of vibration in contrast to noise, further studies are required.

Acknowledgements The authors wish to thank the volunteers for participation in the study. We are grateful to Agneta Agge, Mikael Ögren, Sofie Fredriksson and Josefine Larsson for their valuable assistance in conducting the trial.

Contributors IC, MS and KPW conceived the idea and designed the study. The study was mainly conducted by MS and mainly analysed by IC. The initial draft of the manuscript was prepared by IC and critically revised by KPW and MS. All authors read and approved the final manuscript.

Funding The study was supported by the EU FP7-funded Cargovibes Project. Competing interests None.

Patient consent Obtained.

Ethics approval The study followed the Declaration of Helsinki on Biomedical Research Involving Human Subjects and was approved by the Ethics Committee from the University of Göteborg (920-11).
Provenance and peer review Not commissioned; externally peer reviewed.

Data sharing statement No additional data are available.

\section{REFERENCES}

1. EU. White Paper-European transport policy for 2010: time to decide. Brussels: Commission of the European Communities, 2001.

2. Aasvang GM, Overland B, Ursin R, et al. A field study of effects of road traffic and railway noise on polysomnographic sleep parameters. J Acoust Soc Am 2011;129:3716-26.

3. Miedema HM, Vos H. Associations between self-reported sleep disturbance and environmental noise based on reanalyses of pooled data from 24 studies. Behav Sleep Med 2007;5:1-20.

4. Saremi M, Greneche J, Bonnefond A, et al. Effects of nocturnal railway noise on sleep fragmentation in young and middle-aged subjects as a function of type of train and sound level. Int $J$ Psychophysiol 2008;70:184-91.

5. Tassi P, Rohmer O, Schimchowitsch S, et al. Living alongside railway tracks: long-term effects of nocturnal noise on sleep and cardiovascular reactivity as a function of age. Environ Int 2010;36:683-9.

6. Öhrström E, Gidlöf-Gunnarsson A. Effects of railway noise and vibration in combination: field and laboratory studies. Proceedings of EuroNoise 2009, paper 270, Edinburgh, UK, 2009.

7. Laugsand LE, Strand LB, Platou C, et al. Insomnia and the risk of incident heart failure: a population study. Eur Heart J 2013. Epub 5 March 2013. doi: 10.1093/eurhearti/eht019

8. Eriksson C, Nilsson ME, Willers SM, et al. Traffic noise and cardiovascular health in Sweden: The roadside study. Noise Health 2012;14:140-47.

9. Gula LJ, Krahn AD, Skanes AC, et al. Clinical relevance of arrhythmias during sleep: guidance for clinicians. Heart 2004;90:347-52.

10. Hord DJ, Lubin A, Johnson LC. The evoked heart rate response during sleep. Psychophysiology 1966;3:47-54.

11. Griefahn B, Bröde $P$, Marks A, et al. Autonomic arousals related to traffic noise during sleep. Sleep 2008;31:569-77.

12. Tassi P, Saremi M, Schimchowitsch S, et al. Cardiovascular responses to railway noise during sleep in young and middle-aged adults. Eur J Appl Physiol 2010;108:671-80.

13. Di Nisi J, Muzet A, Ehrhart J, et al. Comparison of cardiovascular responses to noise during waking and sleeping in humans. Sleep 1990;13:108-20.

14. Babisch W. Transportation noise and cardiovascular risk: updated review and synthesis of epidemiological studies indicate that the evidence has increased. Noise Health 2006;8:1-29.

15. Babisch WF, Beule B, Schust $M$, et al. Traffic noise and risk of myocardial infarction. Epidemiology 2005;16:33-40.

16. Grazuleviciene R, Lekaviciute J, Mozgeris G, et al. Traffic noise emissions and myocardial infarction risk. Pol J Environ Stud 2004;13:737-41.

17. Selander J, Nilsson ME, Bluhm G, et al. Long-term exposure to road traffic noise and myocardial infarction. Epidemiology 2009;20:272-9.

18. Sorensen M, Andersen ZJ, Nordsborg RB, et al. Road traffic noise and incident myocardial infarction: a prospective cohort study. PLOS ONE 2012;7:e39283.

19. Basner M, Samel A. Effects of Noctural Aircraft Noise on Sleep Structure. Somnologie 2005;9:84-95.

20. Passchier-Vermeer W. Night-time noise events and awakening Delft, The Netherlands; 2003, TNO Inro report.

21. Franssen E, Van Dongen J, Ruysbroek J, et al. Hinder door milieufactoren en de beoordeling van de leefomgeving in Nederland Inventarisatie verstoringen 2003: TNO, 2004.

22. Meier-Ewert HK, Ridker PM, Rifai N, et al. Effect of sleep loss on C-reactive protein, an inflammatory marker of cardiovascular risk. J Am Coll Cardiol 2004;43:678-83.

23. Babisch W. The noise/stress concept, risk assessment and research Needs. Noise health 2002;4:1-11.

24. Carter NL, Ingham $\mathrm{P}$, Tran $\mathrm{K}$, et al. A field-study of the effects of traffic noise on heart-rate and cardiac-arrhythmia during Sleep. J Sound Vib 1994;169:211-27.

25. Findeis $\mathrm{H}$, Peters $\mathrm{E}$. Disturbing effects of low frequency sound immissions and vibrations in residential buildings. Noise Health 2004;6:29-35.

26. Gidlof-Gunnarsson A, Ogren M, Jerson T, et al. Railway noise annoyance and the importance of number of trains, ground vibration, and building situational factors. Noise Health 2012;14:190-201.

27. Howarth HVC, Griffin MJ. The annoyance caused by simultaneous noise and vibration from railways. $J$ Acoust Soc $A m$ 1991;89:2317-23. 
28. Kiuchi M, Nagata N, Ikeno S, et al. The relationship between the response to external light stimulation and behavioral states in the human fetus: how it differs from vibroacoustic stimulation. Early Hum Dev 2000;58:153-65.

29. Bjor B, Burstrom L, Eriksson K, et al. Mortality from myocardial infarction in relation to exposure to vibration and dust among a cohort of iron-ore miners in Sweden. Occup Environ Med 2010;67:154-8.

30. Bjor B, Burstrom L, Nilsson T, et al. Vibration exposure and myocardial infarction incidence: the VHEEP case-control study. Occup Med (Lond) 2006;56:338-44.

31. WHO. Obesity: Preventing and managing the global epidemic: report of a WHO consultation. Geneva: World Health Organisation, 2000.

32. Smith M, Croy I, Ögren I, et al. On the influence of freight trains on humans: a laboratory investigation of the impact of nocturnal low frequency vibration and noise on sleep and heart rate. PLoS One 2013;8:e55829. doi:10.1371/journal.pone.0055829

33. Iber C, Ancoli-Israel S, Chesson A, et al. The AASM manual for the scoring of sleep and associated events; rules, terminology and technical specifications. 1 edn. Westchester, IL: American Academy of Sleep Medicine, 2007.

34. Basner M, Muller U, Elmenhorst EM. Single and combined effects of air, road, and rail traffic noise on sleep and recuperation. Sleep $2011 ; 34: 11-23$.
35. Basner M, Mueller U, Elmenhorst EM, et al. A systematic comparison of aircraft noise induced EEG awakenings and automatically detected cardic arousals. internoise 2009. Ottawa, Canada, 2009.

36. Keefe FB, Johnson LC, Hunter EJ. EEG and autonomic response pattern during waking and sleep stages. Psychophysiology 1971;8:198-212.

37. Sforza E, Jouny C, Ibanez V. Cardiac activation during arousal in humans: further evidence for hierarchy in the arousal response. Clin Neurophysiol 2000;111:1611-19.

38. Guilleminault C, Abad VC, Stoohs R. Effects of CNS activation on arousal and the autonomic nervous system. Neurology 2004;62:A6.

39. Halasz P. Arousals without awakening-dynamic aspect of sleep. Physiol Behav 1993;54:795-802.

40. Kohler M, Stradling JR. Mechanisms of vascular damage in obstructive sleep apnea. Nat Rev Cardiol 2010;7:677-85.

41. Aasvang GM, Moum T, Engdahl B. Self-reported sleep disturbances due to railway noise: exposure-response relationships for nighttime equivalent and maximum noise levels. $J$ Acoust Soc Am 2008;124:257-68. 